\title{
New Control Strategy for Three-Phase Grid-Connected LCL Inverters without a Phase-Locked Loop
}

\author{
Lin Zhou ${ }^{\dagger}$, Ming Yang*, Qiang Liu*, and Ke Guo* \\ ${ }^{\dagger}$ State Key Laboratory of Power Transmission Equipment \& System Security and New Technology, \\ Chongqing University, Chongqing, China
}

\begin{abstract}
The three-phase synchronous reference frame phase-locked loop (SRF-PLL) is widely used for synchronization applications in power systems. In this paper, a new control strategy for three-phase grid-connected LCL inverters without a PLL is presented. According to the new strategy, a current reference can be generated by using the instantaneous power control scheme and the proposed positive-sequence voltage detector. Through theoretical analysis, it is indicated that a high-quality grid current can be produced by introducing the new control strategy. In addition, a kind of independent control for reactive power can be achieved under unbalanced and distorted grid conditions. Finally, the excellent performance of the proposed control strategy is validated by means of simulation and experimental results.
\end{abstract}

Key words: Control strategy, Grid-connected inverters, Instantaneous power control scheme, LCL filter, Positive-sequence voltage detector

\section{INTRODUCTION}

In recent years, environmental concerns have focused worldwide attention on solar power technology and there is strong support to promote and develop solar power technology. In photovoltaic (PV) technology, and other renewable energy sources like wind power, power electronic inverters play a key role in controlling, managing and delivering power to the power grid [1]. In such a grid-connected mode, the inverter is typically controlled as a current source [2] to inject a certain amount of current into the grid.

Generally, the control strategy used in grid-connected inverters is a cascaded-loop control. The internal current loop regulates the grid current while the external voltage loop controls the dc-link voltage [3], [4]. A control strategy named direct power control (DPC), which is based on a dc-link voltage loop cascaded with an inner power loop instead of a current loop, has been reported in the literature [5]. In this way, the current injected into the utility network is indirectly

Manuscript received Nov. 29, 2012; revised Feb. 28, 2013

Recommended for publication by Associate Editor Jun-Keun Ji.

${ }^{\dagger}$ Corresponding Author: zhoulin@cqu.edu.cn

Tel: +86-23-65102430, Fax: +86-23-65102434, Chongqing University

* State Key Laboratory of Power Transmission Equipment \& System Security and New Technology, Chongqing University, China controlled. Moreover, a control strategy employing an outer power loop and an inner loop has also been reported [6]. Nonlinear control strategies like hysteresis control or dead beat control [7] are preferred due to their high dynamics. As an alternative to these control methods, other control strategies have been proposed in recent publications, such as predictive control [8], [9] and constant-frequency hysteresis control [10].

However, in high-power applications, an alternative filter implementation is achieved with a third-order output filter, such as an LCL filter, which can achieve reduced levels of harmonics distortion at a lower switching frequency and with less total inductance [11]. Thus the cost and weight of the inverter are reduced. On the other hand, due to the need to damp resonances, the filter and the current control design are more complex. Active damping [12] is preferred to passive damping in order to improve the efficiency of conversion. In this case, some control strategies such as the traditional hysteresis control cannot be considered because of active damping and the lower switching frequency. Likewise, in the case of DPC, this approach cannot be used since the switching harmonic spectrum is not clearly defined but spread due to the variable switching frequency. A modified DPC strategy has been proposed allowing the connection of three-phase inverters to the grid through LCL filters [13]. 


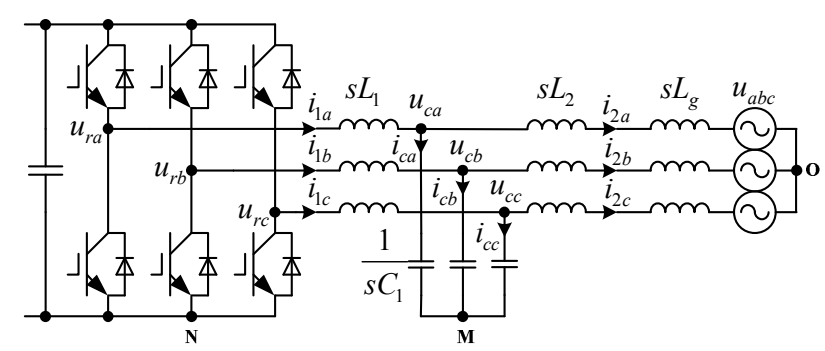

Fig. 1. Grid-connected inverter with an LCL output filter.

In this paper, a new control strategy for three-phase grid-connected LCL inverters without a PLL, which is based on the positive-sequence voltage detector, is proposed. This paper is organized as follows. First, special attention is paid to the description of the three-phase grid-connected LCL power converter, and the choice of the reference frame is analyzed in detail. Second, an instantaneous power control scheme based on the stationary reference frame and the proposed positive-sequence voltage detector for three-phase three-wire systems are presented, giving rise to a new control structure. Next, the new control structure is described and the design parameters of the control system are analyzed. Finally, the theoretical study is validated through simulation and experimental results.

\section{THREE-PHASE GRID-CONNECTED LCL INVERTERS}

\section{A. System Configuration}

In this section, the modeling and analysis of a single three-phase grid-connected inverter with an LCL filter are described. Although LCL filter resonance has already been discussed in the available literature [11]-[13], the aim is to choose the right reference frame in three-phase grid-connected power converters when a third-order LCL filter is used.

The circuit of a three-phase grid-connected LCL inverter is shown in Fig. 1. The series parasitic elements are neglected in both the power components and the grid model for the sake of simplification, where $u_{r a b c}$ are the inverter output voltages, $i_{1 a b c}$ are the inverter side currents, $i_{2 a b c}$ are the grid side currents, $u_{c a b c}$ are the capacitor voltages, $i_{c a b c}$ are the capacitor currents, $L_{g}$ is the grid impedance, and $u_{a b c}$ are the voltage sources.

It is worth noticing that if the three-phase system is symmetrical and balanced, the electric potentials of the M point and $\mathrm{O}$ point are the same. By using the Kirchhoff voltage and current laws, the state equations of an LCL filter in the natural frame can be modeled as:

$$
\left\{\begin{array}{l}
L_{1} \frac{d i_{1 k}}{d t}=u_{r k}-u_{c k} \\
C_{1} \frac{d u_{c k}}{d t}=i_{1 k}-i_{2 k} \\
\left(L_{2}+L_{g}\right) \frac{d i_{2 k}}{d t}=u_{c k}-u_{k}
\end{array}\right.
$$

where $k=a, b, c$ represents the three-phase natural frame.

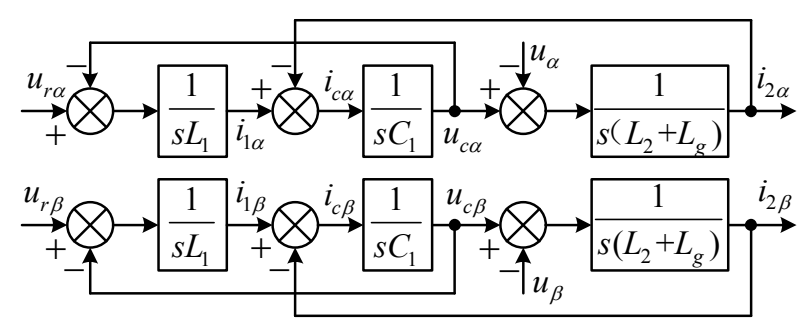

Fig. 2. Mathematical model of LCL filter in stationary reference frame.

\section{B. The Choice of the Reference Frame}

Nowadays, a high proportion of the three-phase power converters are connected to three-phase three-wire networks. Hence only two current controllers are necessary since the third current is given by the Kirchhoff current law. In order to reduce the complexity of the control system, the control loops can be structured in the stationary reference frame using the Clarke transformation $\left[T_{\alpha \beta}\right]$ or in the synchronous reference frame using the Park transformation $\left[T_{d q}\right]$, where $\left[T_{\alpha \beta}\right]$ and $\left[T_{d q}\right]$ are given by:

$\left[T_{\alpha \beta}\right]=\frac{2}{3}\left[\begin{array}{ccc}1 & -1 / 2 & -1 / 2 \\ 0 & \sqrt{3} / 2 & -\sqrt{3} / 2\end{array}\right],\left[T_{d q}\right]=\left[\begin{array}{cc}\cos \theta & \sin \theta \\ -\sin \theta & \cos \theta\end{array}\right]$

By using the Clarke transformation $\left[T_{\alpha \beta}\right]$, the state equations of the LCL filter in the stationary frame can be written as:

$$
\left\{\begin{array}{l}
\frac{d i_{1 \alpha}}{d t}=\frac{1}{L_{1}} u_{r \alpha}-\frac{1}{L_{1}} u_{c \alpha}, \frac{d i_{1 \beta}}{d t}=\frac{1}{L_{1}} u_{r \beta}-\frac{1}{L_{1}} u_{c \beta} \\
\frac{d u_{c \alpha}}{d t}=\frac{1}{C_{1}} i_{1 \alpha}-\frac{1}{C_{1}} i_{2 \alpha}, \frac{d u_{c \beta}}{d t}=\frac{1}{C_{1}} i_{1 \beta}-\frac{1}{C_{1}} i_{2 \beta} \\
\frac{d i_{2 \alpha}}{d t}=\frac{1}{L_{2}+L_{g}}\left(u_{c \alpha}-u_{\alpha}\right), \frac{d i_{2 \beta}}{d t}=\frac{1}{L_{2}+L_{g}}\left(u_{c \beta}-u_{\beta}\right)
\end{array}\right.
$$

According to (3), the mathematical model of the LCL filter in the stationary reference frame is shown in Fig. 2.

Another possible way to structure the control loops is to use the synchronous reference frame. In this case, by using the Park transformation $\left[T_{d q}\right]$, transforming (3) into the synchronous reference frame gives rise to the following state equations:

$$
\left\{\begin{array}{l}
\frac{d i_{1 d}}{d t}=\frac{1}{L_{1}} u_{r d}-\frac{1}{L_{1}} u_{c d}+\omega i_{1 q}, \frac{d i_{1 q}}{d t}=\frac{1}{L_{1}} u_{r q}-\frac{1}{L_{1}} u_{c q}-\omega i_{1 d} \\
\frac{d u_{c d}}{d t}=\frac{1}{C_{1}} i_{1 d}-\frac{1}{C_{1}} i_{2 d}+\omega u_{c q}, \frac{d u_{c q}}{d t}=\frac{1}{C_{1}} i_{1 q}-\frac{1}{C_{1}} i_{2 q}-\omega u_{c d} \\
\frac{d i_{2 d}}{d t}=\frac{1}{L_{2}+L_{g}}\left(u_{c d}-u_{d}\right)+\omega i_{2 q}, \frac{d i_{2 q}}{d t}=\frac{1}{L_{2}+L_{g}}\left(u_{c q}-u_{q}\right)-\omega i_{2 d}
\end{array}\right.
$$

According to (4), the mathematical model of the LCL filter in the synchronous reference frame is shown in Fig. 3. 


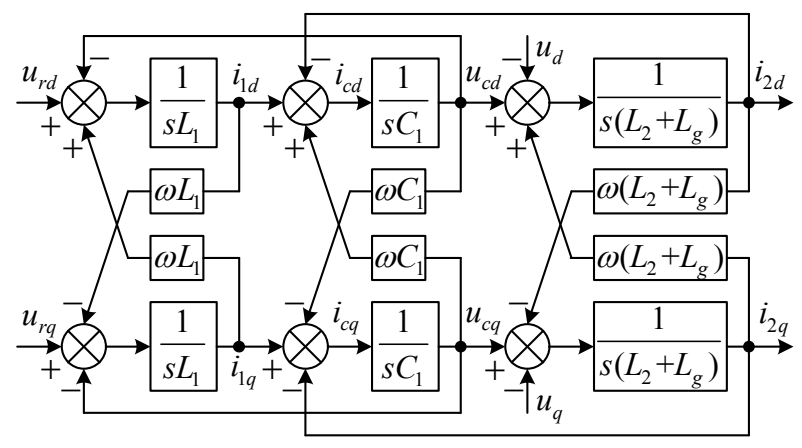

Fig. 3. Mathematical model of LCL filter in synchronous reference frame.

By comparing the mathematical models shown in Fig.2 and Fig.3, it can be seen that there are six cross-coupling terms, and that decoupling control is the major drawback in the synchronous reference frame. Moreover, the phase angle of the grid voltage is necessary in this implementation. However, in the case of the mathematical model shown in Fig.2, things are different. Each phase can be independent controlled. Additionally, if PR controllers are used for current regulation, the complexity of the control becomes lower when compared to the model shown in the synchronous reference frame.

\section{INSTANTANEOUS POWER CONTROL SCHEME BASED ON THE STATIONARY REFERENCE FRAME}

By applying the instantaneous power theory, the active and reactive powers in the stationary reference frame can be written as:

$$
\left[\begin{array}{l}
\mathrm{P} \\
Q
\end{array}\right]=\frac{3}{2}\left[\begin{array}{cc}
u_{\alpha} & u_{\beta} \\
u_{\beta} & -u_{\alpha}
\end{array}\right]\left[\begin{array}{l}
i_{\alpha} \\
i_{\beta}
\end{array}\right] .
$$

From (5), the current reference can be expressed as:

$$
\left[\begin{array}{c}
i_{\alpha}^{*} \\
i_{\beta}^{*}
\end{array}\right]=\frac{2}{3}\left[\begin{array}{cc}
u_{\alpha} & u_{\beta} \\
u_{\beta} & -u_{\alpha}
\end{array}\right]^{-1}\left[\begin{array}{l}
\mathrm{P} \\
Q
\end{array}\right]=\frac{2 / 3}{u_{\alpha}^{2}+u_{\beta}^{2}}\left[\begin{array}{cc}
u_{\alpha} & u_{\beta} \\
u_{\beta} & -u_{\alpha}
\end{array}\right]\left[\begin{array}{l}
\mathrm{P} \\
Q
\end{array}\right] .
$$

Most of the PV inverters designed for grid-interconnected service operate normally at a unity power factor. In this case, the reactive power control is not allowed, e.g., by making $Q=0$, the current reference in the $\alpha \beta$ reference frame will be given by:

$$
\left[\begin{array}{c}
i_{\alpha}^{*} \\
i_{\beta}^{*}
\end{array}\right]=\frac{2}{3} \frac{\mathrm{P}}{u_{\alpha}^{2}+u_{\beta}^{2}}\left[\begin{array}{l}
u_{\alpha} \\
u_{\beta}
\end{array}\right] .
$$

However, in case of a grid fault, the inverters can deliver reactive power and control the active and reactive power according to the low-voltage ride-through requirements given by the grid codes. In addition, in the case of PV implementation, the input power of the inverters is decided by the maximum power point tracking of the PV array, and energy can only flow one-way. As a consequence, independent control

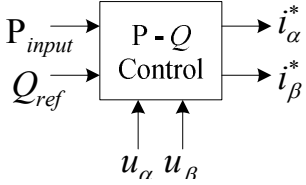

Fig. 4. Instantaneous power control scheme based on the stationary reference frame.

of the reactive power can be achieved by the traditional instantaneous power theory. By using (6), the instantaneous power control scheme based on the stationary reference frame can be expressed as in Fig. 4.

In this case, the current reference can be generated by using the instantaneous power control scheme based on the instantaneous power theory. Moreover, working in the $\alpha \beta$ reference frame, the phase angle information is not a necessity, and the filtered grid voltages can be used as a template for the reference current calculation. In addition, the power control scheme will provide inductive reactive power when $Q_{\text {ref }}>0$, and it will provide capacitive reactive power when $Q_{r e f}<0$.

Although the grid voltage waveforms are sinusoidal and balanced under regular operating conditions, they can easily become unbalanced and distorted due to the effects of grid faults or nonlinear loads. Under these conditions, precise and fast detection of the instantaneous positive-sequence voltage component for the reference current calculation is necessary in order to stay actively connected, support the grid services and keep the generation up and running [14]-[16].

\section{Designed Positive-SeQuence Voltage DETECTOR}

Precise characterization of the grid voltage is a crucial issue in order to ensure the quality of the power that is delivered from the PV systems to the grid. In this paper, such characterization is performed by means of a positive-sequence voltage detector based on a double resonant filter.

\section{A. Detection Principle of the Positive-Sequence Component}

In unbalanced grid operating conditions (without voltage harmonics), the three-phase voltage vector can be split into its instantaneous positive-, negative-, and zero-sequence components, which can be expressed as:

$$
\begin{aligned}
u_{i} & =u^{+1} \cos \left(\omega t-k \frac{2}{3} \pi\right) \\
& +u^{-1} \cos \left(\omega t+k \frac{2}{3} \pi+\phi^{-1}\right)+u^{0} \cos \left(\omega t+\phi^{0}\right)
\end{aligned}
$$

where the superscripts $+1,-1$ and 0 define the coefficients for the positive-, negative-, and zero-sequence components, and $k$ takes the values $k=0,1,2$ for $i=\mathrm{a}, \mathrm{b}$, c, respectively.

Most of the three-phase grid-connected power converters employ a three-wire connection. Therefore, using the Clarke transformation, the utility voltage can be given by: 


$$
\left[\begin{array}{l}
u_{\alpha} \\
u_{\beta}
\end{array}\right]=\left[T_{\alpha \beta}\right]\left[\begin{array}{l}
u_{a} \\
u_{b} \\
u_{c}
\end{array}\right]=u^{+1}\left[\begin{array}{l}
\cos (\omega t) \\
\sin (\omega t)
\end{array}\right]+u^{-1}\left[\begin{array}{c}
\cos \left(\omega t+\phi^{-1}\right) \\
-\sin \left(\omega t+\phi^{-1}\right)
\end{array}\right] \text {. }
$$

From (9), it can be seen that the zero-sequence component was eliminated on the $\alpha \beta$ reference frame, which cannot be controlled in three-phase three-wire power converters. Moreover, (9) can be rearranged in the following form:

$$
\left[\begin{array}{l}
u_{\alpha} \\
u_{\beta}
\end{array}\right]=u^{+1}\left[\begin{array}{c}
\cos (\omega t) \\
\cos \left(\omega t-\frac{\pi}{2}\right)
\end{array}\right]+u^{-1}\left[\begin{array}{c}
\cos \left(\omega t+\phi^{-1}\right) \\
-\cos \left(\omega t+\phi^{-1}-\frac{\pi}{2}\right)
\end{array}\right] .
$$

Then, the $90^{\circ}$ shifted versions of $u_{\alpha}$ and $u_{\beta}$ in (10) can be expressed as follows:

$$
\left[\begin{array}{c}
u_{\alpha}^{\prime} \\
u_{\beta}^{\prime}
\end{array}\right]=u^{+1}\left[\begin{array}{c}
\cos \left(\omega t-\frac{\pi}{2}\right) \\
-\cos (\omega t)
\end{array}\right]+u^{-1}\left[\begin{array}{c}
\cos \left(\omega t+\phi^{-1}-\frac{\pi}{2}\right) \\
\cos \left(\omega t+\phi^{-1}\right)
\end{array}\right] .
$$

Finally, according to (10) and (11), the instantaneous positive-sequence voltage component in the $\alpha \beta$ reference frame can be calculated by:

$$
\left[\begin{array}{c}
u_{\alpha}^{+1} \\
u_{\beta}^{+1}
\end{array}\right]=u^{+1}\left[\begin{array}{c}
\cos (\omega t) \\
\sin (\omega t)
\end{array}\right]=\frac{1}{2}\left[\begin{array}{l}
u_{\alpha}-u_{\beta}^{\prime} \\
u_{\beta}+u_{\alpha}^{\prime}
\end{array}\right] .
$$

\section{B. The Design of the Positive-Sequence Voltage Detector}

Although a $90^{\circ}$ lagging phase-shifting of a sinusoidal signal can be achieve by using an integrator or a differentiator, the initial value of the integrator is uncertain, and the differentiator is difficult to implement. In this paper, a first-order all-pass filter was used to achieve the $90^{\circ}$ phase-shifting of the $u_{\alpha}$ and $u_{\beta}$ signals as follows:

$$
H(s)=\frac{\omega_{1}-s}{\omega_{1}+s} .
$$

Fig. 5 shows the Bode plot of the transfer function of (13). As Fig. 5 clearly shows, the signal is always $90^{\circ}$ lagging when the input frequency $\omega=\omega_{1}$. If the input frequency varies $\Delta \omega= \pm 0.5 \times 2 \pi \mathrm{rad} / \mathrm{s}$ when a fault occurs, the phase error is only $\left|\Delta \phi_{H}\right|=0.27^{\circ}$. From the results, it can be concluded that the $90^{\circ}$ phase shifter can easily achieve the $90^{\circ}$ shifted versions when the grid frequency varies within a permissible range, e.g., $f=50 \pm 0.5 \mathrm{~Hz}$.

It is worth noting that the premise of detecting the positive-sequence component by (12) is possible since the grid voltage does not consider the harmonic components. Therefore, in order to filter the harmonic components, a new filter called a double resonant filter was proposed in this paper. The proposed filter diagram is shown in Fig. 6.

The double resonant filter is a fourth-order band-pass filter, and its transfer function is given by:

$$
D(s)=\frac{2 k^{2} s^{2}}{s^{4}+2 k s^{3}+\left(2 k^{2}+2 \omega_{1}^{2}\right) s^{2}+2 k \omega_{1}^{2} s+\omega_{1}^{4}}
$$

where $\omega_{1}$ and $k$ are the resonance frequency and the damping factor of the filter.

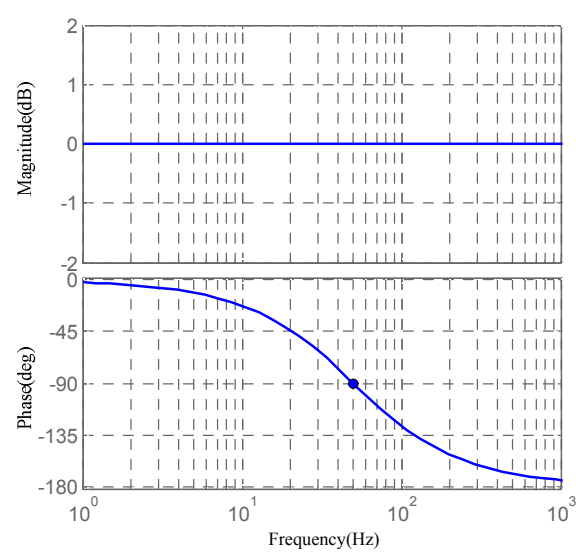

Fig. 5. Bode plots of the $90^{\circ}$ phase shifter.

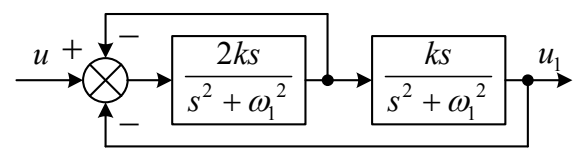

Fig. 6. Structure of the double resonant filter.

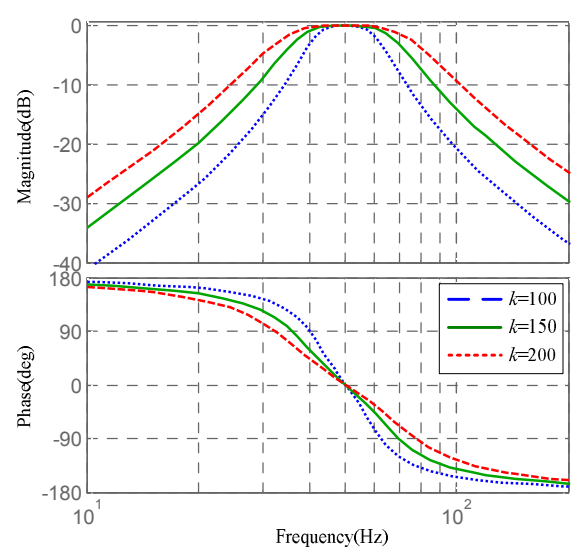

Fig. 7. Bode plots of the double resonant filter for different values of $k$.

Bode plots from the transfer function of (14) are shown in Fig. 7 for several values of $k$. The plot shows that the higher the value of $k$, the faster the response of the filter. However, the gain $k$ also affects the bandwidth of the filter. A very high value for $k$ would reduce the immunity of the filter in terms of the harmonics in the input. On the other hand, a very low value for $k$ gives rise to a very long transient response of the filter. Therefore, a reasonable value for $k$ should be selected between the dynamic response and the harmonic rejection based on the actual situation.

From the plots shown in Fig. 7, and considering that the actual grid voltage mainly contains the $5^{\text {th }}$ and $7^{\text {th }}$ harmonics in three-phase three-wire power converters, a better tradeoff between the dynamic response and the harmonic rejection can be achieved with $k=150$. In this case, the response time of the filter is $t_{s} \approx 32 \mathrm{~ms}$, and the attenuation of the filter at $250 \mathrm{~Hz}$ is $-34 \mathrm{~dB}$. In addition, the phase error is only $\left|\Delta \phi_{\mathrm{D}}\right|=2^{0}$ when the input frequency varies $\Delta \omega= \pm 0.5 \times 2 \pi \mathrm{rad} / \mathrm{s}$. Therefore, this value of $k=150$ results in an interesting selection in terms of harmonic rejection and response time. 


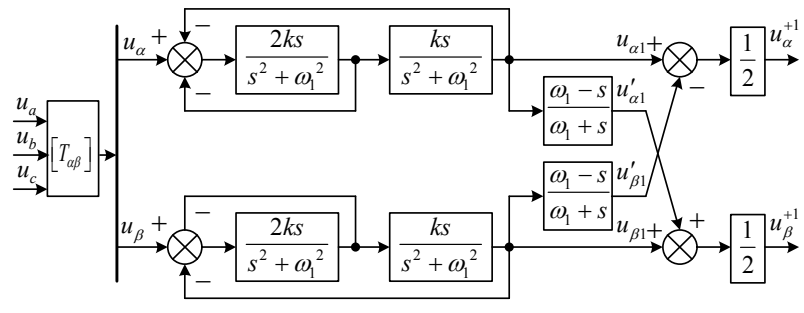

Fig. 8. Block diagram of the positive-sequence voltage detector.

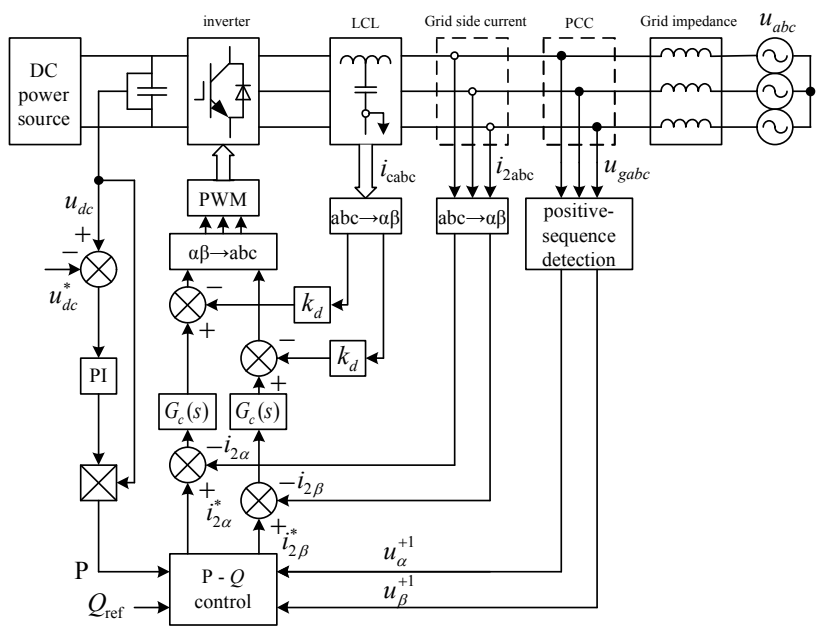

Fig. 9. Block diagram of the control system with LCL filter.

Finally, according to (12), (13), and Fig.6, a block diagram of the proposed positive-sequence voltage detector in this paper is shown in Fig. 8.

As shown in Fig. 8, by using the Clarke transformation, only two double resonant filters are necessary to filter the harmonic components in three-phase applications, one for $\alpha$ and the other for $\beta$. Moreover, because of the super harmonic attenuation function of the double resonant filter, the proposed positive-sequence voltage detector can be considered in an unbalanced and highly distorted three-phase grid voltage.

\section{Proposed CONTROL StRATEGY}

Either the inverter side current or the grid side current of the LCL filter can be controlled. Each alternative has its own advantages and drawbacks. Depending on the controlled current, specific active damping techniques have been proposed.

\section{A. The Structure of the Control System}

Considering that the instantaneous power control scheme based on the stationary reference frame, expressed in Fig. 4, and the proposed positive-sequence voltage detector, shown in Fig.8, it can be seen that if the grid side current is controlled, and the corresponding capacitor current active damping technique is chosen, the complete block diagram that is shown in Fig. 9 shows the concept of the proposed control approach.

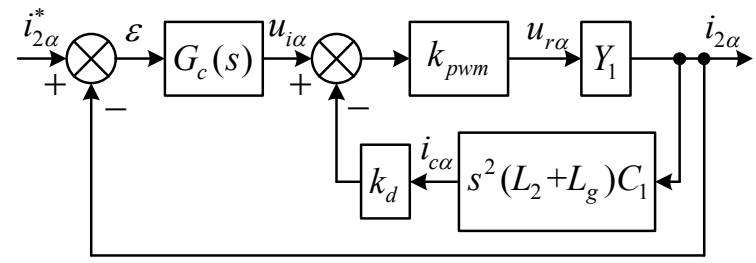

Fig. 10. Control loop for the grid side current with feedback of the capacitor current for active damping filter.

TABLE I

INVERTER SySTEM PARAMETER VALUES

\begin{tabular}{|c|c|}
\hline Quantity & Value \\
\hline Rated output power $\mathrm{P}_{1}$ & $5[\mathrm{~kW}]$ \\
\hline Switching frequency $f_{\text {sw }}$ & $10[\mathrm{kHz}]$ \\
\hline DC-link voltage $U_{d c}$ & $680[\mathrm{~V}]$ \\
\hline Inverter side inductance $L_{1}$ & $4.58[\mathrm{mH}]$ \\
\hline Filter capacitance $C_{1}$ & $4.7[\mu \mathrm{F}]$ \\
\hline Grid side inductance $L_{2}$ & $0.92[\mathrm{mH}]$ \\
\hline Grid impedance $L_{g}$ & $0.012[\mathrm{mH}]$ \\
\hline Nominal grid voltage $u_{g}$ & $220\left[\mathrm{~V}_{\mathrm{rms}}\right]$ \\
\hline
\end{tabular}

As shown in Fig. 9, $k_{d}$ is the damping factor of the capacitor current, $u_{g a b c}$ are the actual grid voltages in the connection point, and $G_{c}(s)$ is the current controller of the control system. The basic idea of the proposed control approach is that the current reference can be generated by using the instantaneous power control scheme and the proposed positive-sequence voltage detector. In addition, the computational cost of the control system can be reduced since no trigonometric transformations are performed.

\section{B. Parameters Design of the Control System}

The design procedure of the LCL filter is beyond of the scope of this paper. For further research, the study in [11] may be consulted. The following analysis is based on the full-bridge three-phase inverter parameter values listed in Table I. It is worth mentioning that these parameters have been extracted from a laboratory prototype.

As shown in Fig. 9, the control structure between the $\alpha$ phase and the $\beta$ phase does not contain cross-coupling terms. Therefore, in the following parameters design of the control system can only be discussed in the $\alpha$ phase. In this case, the control diagram shown in Fig. 9 can be depicted in Fig. 10.

As can be observed in Fig. 10, the feedback path of the capacitor current for active damping purposes is implemented. The transfer function $Y_{1}$ between the grid side current $i_{2 \alpha}$ and the inverter output voltage $u_{r \alpha}$ is easily obtained from Fig. 2 .

$$
Y_{1}=\frac{i_{2 \alpha}}{u_{r \alpha}}=\frac{1}{s^{3} L_{1}\left(L_{2}+L_{g}\right) C_{1}+s\left(L_{1}+L_{2}+L_{g}\right)} .
$$

In Fig.10, the transfer function $k_{p w m}$ is the gain of the full-bridge three-phase inverter, and can be approximated by: 


$$
k_{p w m}=\frac{U_{d c}}{2} .
$$

Since the control variables are sinusoidal in this situation and due to the known drawback of PI controllers in failing to remove steady-state errors when controlling sinusoidal waveforms, employment of a proportional resonant (PR) controller is necessary, and the PR controller is defined as:

$$
G_{P R}(s)=k_{p}+\frac{2 k_{i} \omega_{c} s}{s^{2}+2 \omega_{c} s+\omega_{1}^{2}}
$$

where $k_{p}$ is the proportional gain, $k_{i}$ is the integral gain, $\omega_{1}$ is the resonance frequency of the controller, and the bandwidth of the controller is decided by $\omega_{c}$.

In addition, harmonic compensation (HC) can be achieved by cascading several generalized integrators tuned to resonate at a desired frequency. Therefore, the current controller shown in Fig. 10 can be expressed by:

$$
G_{c}(s)=k_{p}+\sum_{h=1,5,7} \frac{2 k_{i h} \omega_{c} s}{s^{2}+2 \omega_{c} s+\left(h \omega_{1}\right)^{2}} .
$$

As a result, according to the control loop shown in Fig.10, the loop gain of the control system can be written as:

$$
\left\{\begin{array}{l}
T=G_{c}(s) \cdot \frac{k_{p w m}}{s^{3} L_{1} L_{2}{ }^{\prime} C_{1}+s^{2} k_{p w m} k_{d} L_{2}{ }^{\prime} C_{1}+s\left(L_{1}+L_{2}{ }^{\prime}\right)} \\
L_{2}{ }^{\prime}=L_{2}+L_{g}
\end{array}\right.
$$

By putting the open-loop control-to-output transfer function into the standard normalized quadratic form, the damping ratio $\zeta$ can be given by:

$$
\zeta=\frac{k_{d} k_{p w m}}{2} \sqrt{\frac{\left(L_{2}+L_{g}\right) C_{1}}{L_{1}\left(L_{1}+L_{2}+L_{g}\right)}} .
$$

Although the higher the value of $\zeta$, the better the damping effect, a very high value for $\zeta$ will reduce the stability margin of the system. Thus a better tradeoff can be achieved with $\zeta=0.707$, and $k_{d}$ can be indirectly calculated by (20).

Finally, according to the inverter parameter listed in Table I and the above analysis, the control parameters of Table II can be used, and a Bode plot of the loop gain $T$ is shown in Fig. 11.

From the Bode plot depicted in Fig. 11, it can be observed that the phase margin (PM) is approximately equal to $57.7^{0}$ at a crossover frequency (CF) of $518 \mathrm{~Hz}$, indicating a high stability and dynamic response.

\section{The Effect of Grid Impedance}

An increasingly important concern for grid-connected inverters is the effect of grid impedance on inverter control performance and stability. Usually, the value of the grid impedance is far less than that of the grid side inductance under stiff grid conditions (see Table I), and the effect of the grid impedance on the inverter control performance can be ignored. However, the grid impedance value may become high under weak grid conditions. In this case, a Bode plot of the loop gain

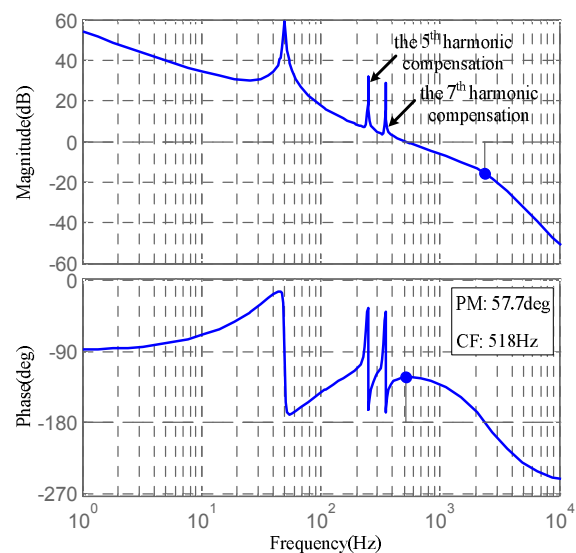

Fig. 11. Bode plot of the loop gain $\mathrm{T}$ with $\mathrm{PR}+\mathrm{HC}$ controller.

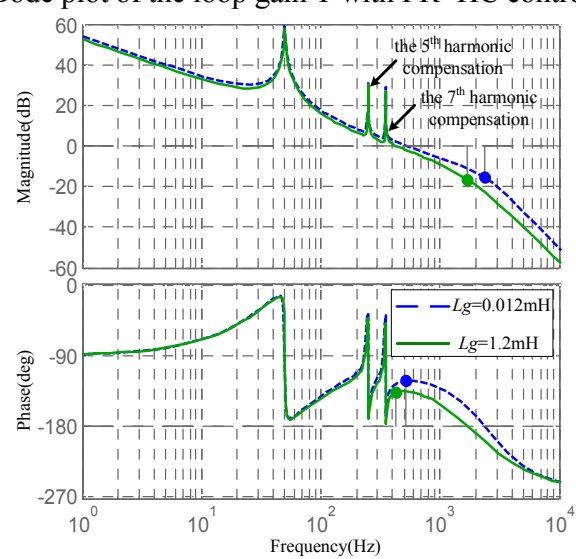

Fig. 12. Bode plot of the loop gain $T$ when the grid impedance increases.

TABLE II

Control System Parameter VAlues

\begin{tabular}{|c|c|}
\hline Parameter & Value \\
\hline$k_{d}$ & 0.3 \\
\hline$k_{p}$ & 0.055 \\
\hline$k_{i 1}$ & 5 \\
\hline$k_{i 5}$ & 1 \\
\hline$k_{i 7}$ & 1 \\
\hline$\omega_{c}$ & $\pi$ \\
\hline
\end{tabular}

$T$ considering different values of $L_{g}$ has been depicted in Fig. 12.

From the Bode plot depicted in Fig. 12, it can be observed that the PM and the CF have been reduced with an increase of the grid impedance, and that the system can become unstable due to the reduced bandwidth or the change in the resonance frequency.

On the other hand, as the power range of the PV inverters increases, the effect of grid impedance becomes more and more obvious. According to the block diagram shown in Fig. 9, the relationship between the actual grid voltage $u_{g a}$ and the voltage source $u_{a}$ is given by:

$$
L_{g} \frac{d i_{2 a}}{d t}=u_{g a}-u_{a} .
$$




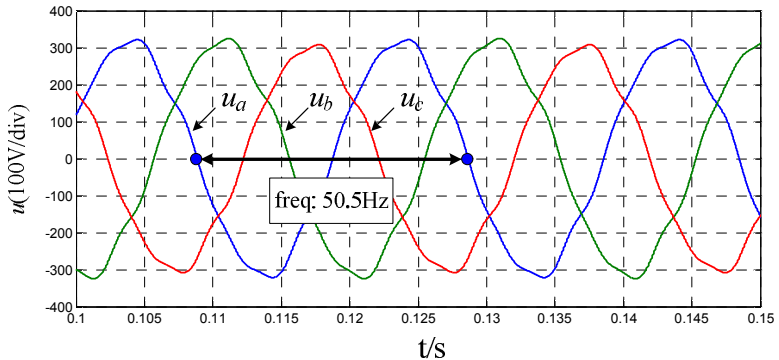

(a)

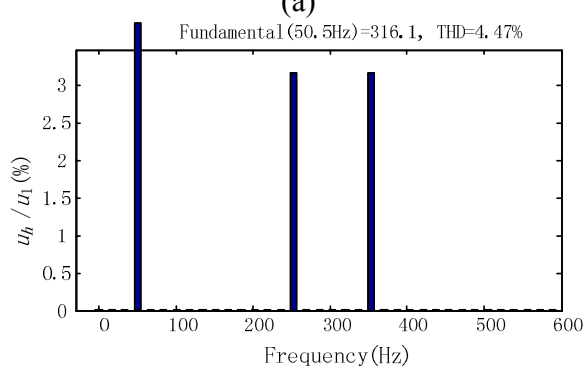

(b)

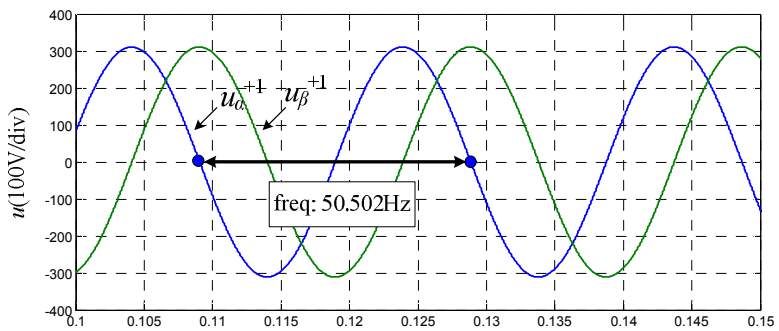

$\mathrm{t} / \mathrm{s}$

(c)

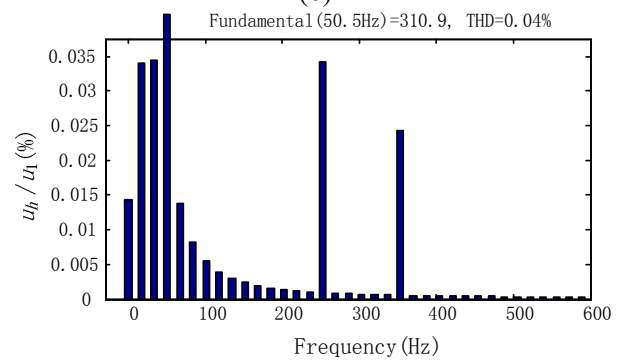

(d)

Fig. 13. Response of the positive-sequence voltage detector under unbalanced and distorted conditions. (a) Utility voltage. (b) Harmonic spectrum of the utility voltage. (c) Detected positive-sequence signals. (d) Harmonic spectrum of the detected positive-sequence signals.

In (21), it can be seen that there is a phase difference between $i_{2 a}$ and $u_{a}$. It can also be seen that the grid current phase is indirectly affected by the grid impedance and the grid power. That is why the control of the reactive power becomes more important in high-power applications.

\section{Simulation RESULtS}

In order to confirm the effectiveness of the proposed system, a MATLAB/SIMULINK model has been implemented. The electrical parameters for the simulation model are given in Table I and Table II.

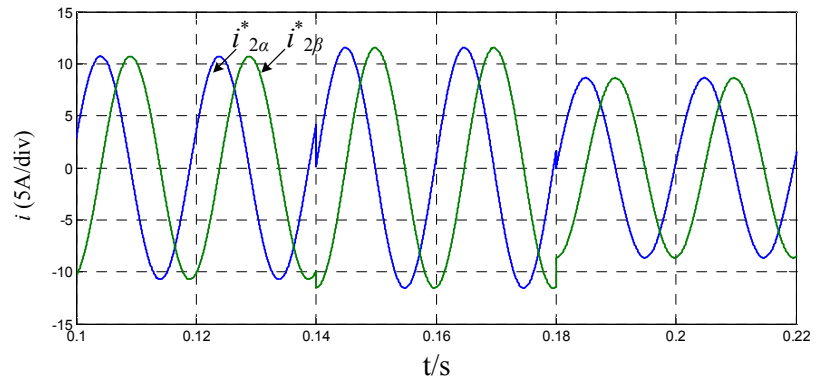

(a)

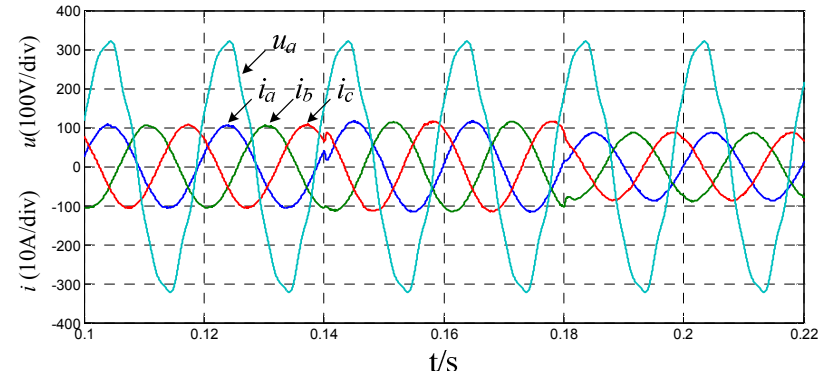

(b)

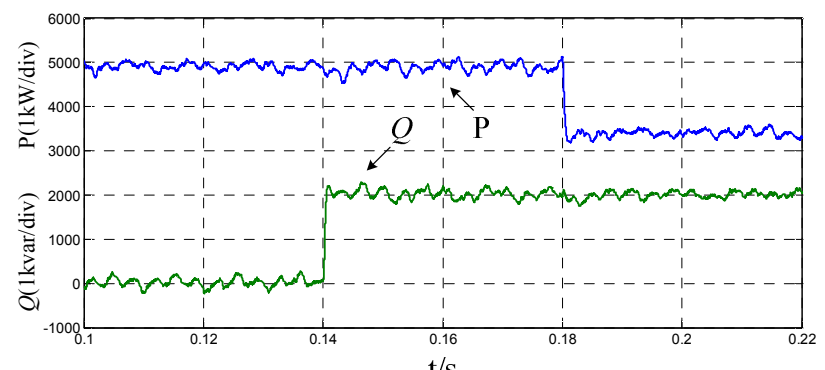

(c)

Fig. 14. Simulation results of the proposed control system. (a) Generated current reference signals. (b) A-phase grid voltage and three-phase current. (c) Actual active and reactive powers.

First, an unbalanced and highly distorted three-phase grid voltage was considered in the simulation for demonstrating the excellent performance of the proposed positive-sequence voltage detector with $k=150$. In this case, the fundamental frequency was set to $50.5 \mathrm{~Hz}$, and the positive- and negative-sequence voltage at the fundamental frequency were set to $u^{+1}=311 \mathrm{~V}, \phi^{+1}=0^{0}$ and $u^{-1}=10 \mathrm{~V}, \phi^{-1}=60^{0}$. In terms of the harmonics, they were set to $u^{-5}=10 \mathrm{~V}, \phi^{-5}=-45^{0}$ and $u^{+7}=10 \mathrm{~V}, \phi^{+7}=30^{0}$ for the $5^{\text {th }}$ and $7^{\text {th }}$ harmonics, respectively.

In Fig. 13(a), the waveforms of the unbalanced and distorted grid voltage considered in this simulation are depicted. Fig. 13(c) shows the positive-sequence component detected by the proposed positive-sequence voltage detector, and the frequency error is only $|\Delta f|=0.002 \mathrm{~Hz}$. Likewise, the respective harmonic spectrums are drawn in Fig. 13(b) and (d). From the results shown in Fig. 13, it can be concluded that the proposed positive-sequence voltage detector is a very precise and fast synchronization system. The detected instantaneous positive-sequence component can be used to calculate the current reference through (6). 


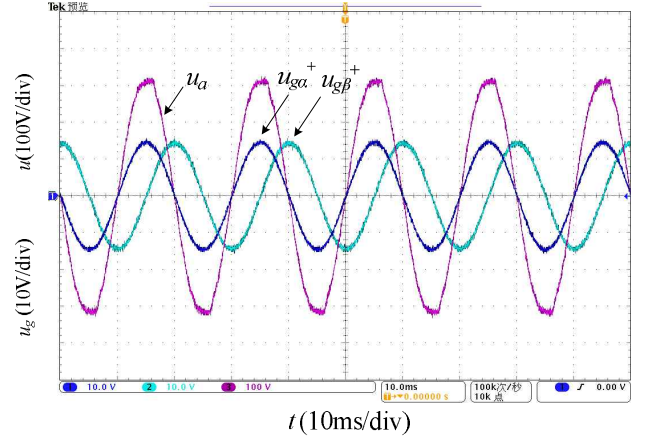

(a)

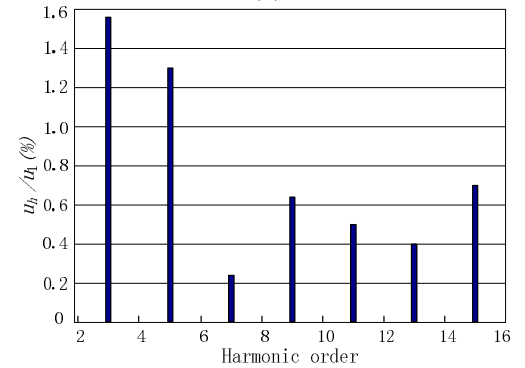

(b)

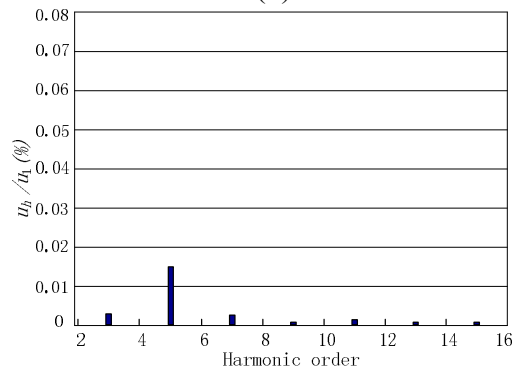

(c)

Fig. 15. Experimental results of the positive-sequence voltage detector under actual grid operating conditions. (a) Utility voltage and the detected positive-sequence signals. (b) Harmonic spectrum of the utility voltage. (c) Harmonic spectrum of the detected positive-sequence signals.

Second, the control system shown in Fig. 9 was tested under the aforementioned unbalanced and polluted grid conditions. In this simulation, a step change from 0kvar to $2 \mathrm{kvar}$ occurs in the inductive reactive power reference value $Q_{\text {ref }}$ at $t=0.14 \mathrm{~s}$, and another step change from $5 \mathrm{kw}$ to $3.5 \mathrm{~kW}$ occurs in the active power reference value $\mathrm{P}_{\text {input }}$ at $t=0.18 \mathrm{~s}$.

Fig. 14 shows the simulation results of the proposed control system with an LCL filter. The plot in Fig. 14(a) shows the current reference generated by using the instantaneous power control scheme. In turn, Fig. 14(b) shows the grid current and the voltage waveforms. From the results, it can be seen that the grid current lags behind the voltage when the reactive power reference changes at $t=0.14 \mathrm{~s}$, and the amplitude of the grid current increases slightly. Additionally, in order to maintain a constant reactive power, the grid current further lags behind the voltage when the active power reference reduced at $t=0.18 \mathrm{~s}$. Finally, Fig. 14(c) shows the tracking results of the actual active and reactive power, which match the power reference value.

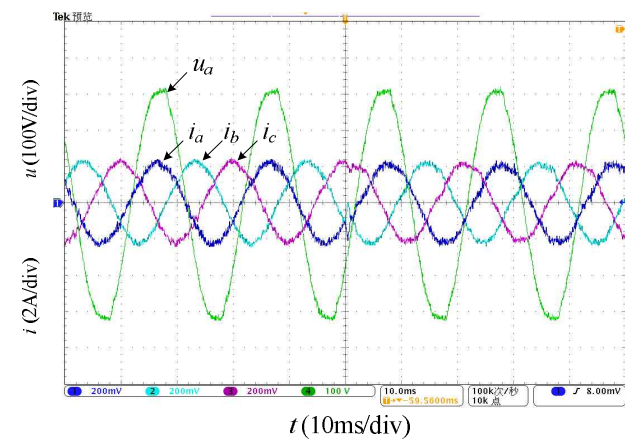

(a)

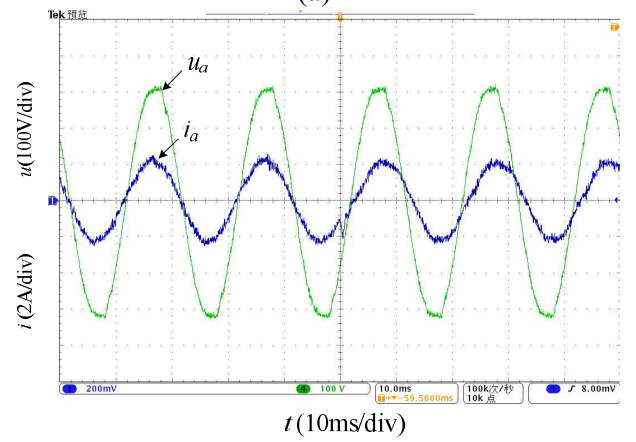

(b)

Fig. 16. Experimental results of a step in the reactive power reference. (a) A-phase grid voltage and three-phase current. (b) A-phase grid voltage and A-phase current.

\section{EXPERIMENTAL RESULTS}

To experimentally validate the performance of the proposed control system, a prototype of the system, depicted in Fig. 9, has been constructed on a DG test-bed. Additionally, the algorithm of the control system is implemented by RT-LAB, and the sampling period is set to $12 \mu \mathrm{s}$.

In the first experiment, the capability of the proposed positive-sequence voltage detector with $k=150$ online detecting the positive-sequence component was tested. Considering that the peak value signals of the RT-LAB analog output channel shown on a digital oscilloscope are $15 \mathrm{~V}$, the magnitude of the detected positive-sequence component shown in Fig. 15(a) has been attenuated $\left(u_{g \alpha}{ }^{+}\right.$and $u_{g \beta}{ }^{+}$represent the attenuated signals). As can be noted in Fig. 15(b) and (c), although the actual grid voltage waveforms are distorted, the harmonic analysis shows that the detected positive-sequence voltage waveforms are nearly sine wave in shape, which indicates a precise estimation.

In the second experiment, the capability of the control system shown in Fig. 9 was tested under actual grid conditions. The practical measured waveforms are shown in Fig. 16 and Fig. 17.

Fig. 16 shows that the experimental results of the reactive power reference experienced a sudden jump from 0kvar to $0.5 \mathrm{kvar}$. From the results, it can be seen that the current waveforms are in-phase with the grid voltage initially. However, at the end, the current waveforms lag behind the voltage due to the step change of the reactive power reference. 


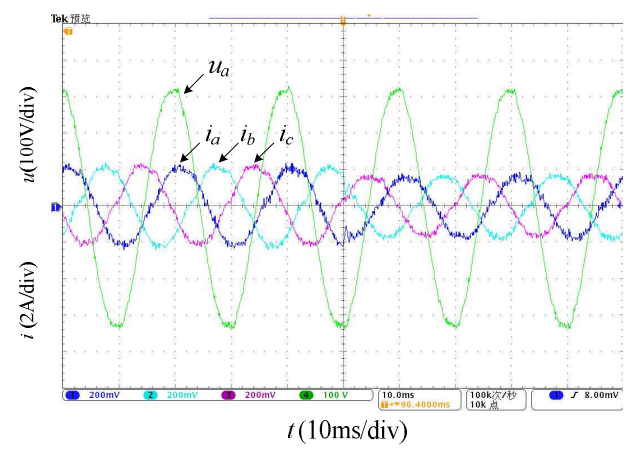

(a)

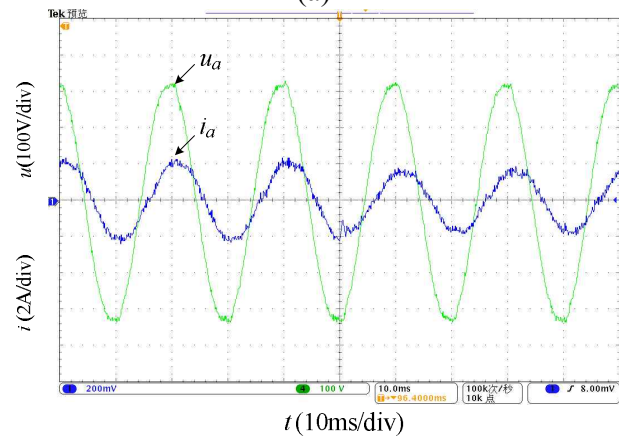

(b)

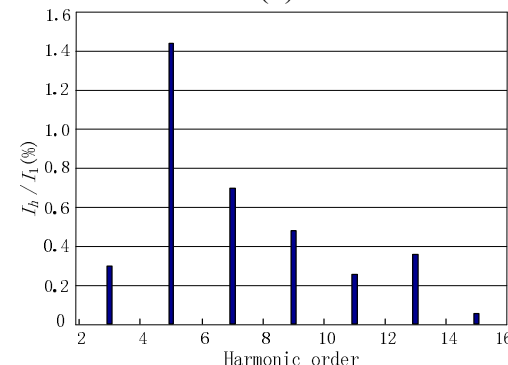

(c)

Fig. 17. Experimental results of a step in the active power reference. (a) A-phase grid voltage and three-phase current. (b) A-phase grid voltage and A-phase current. (c) Harmonic spectrum of the grid current.

In addition, as shown in Fig. 17, in order to maintain a constant reactive power, the grid current further lags behind the voltage when the active power reference is reduced, which demonstrates its excellent performance.

\section{CONCLUSIONS}

A new control structure for three-phase grid-connected voltage source inverters (VSI) with an LCL-filter is proposed. By using the instantaneous power control scheme and the proposed positive-sequence voltage detector, the current reference can be indirectly generated, which avoids the complex PLL. The effectiveness of the proposed system for three-phase grid-connected VSIs is demonstrated via simulation results, which show a significant improvement in both the steady state and transient behavior. The same behavior is experimentally verified. The fast dynamic response to a reference step is not affected by the inclusion of additional control loops. Good performance is guaranteed even under unbalanced and distorted grid voltages.

\section{ACKNOWLEDGMENT}

This research work was supported by the National High Technology and Development Program (863 Program) of China under Project 2011AA05A301.

\section{REFERENCES}

[1] X. Wang, J. M. Guerrero, F. Blaabjerg, and Z. Chen, "A review of power electronics based microgrids," Journal of Power Electronics, Vol. 12, No. 1, pp. 181-192, Jan. 2012.

[2] S. Peng, A. Luo, Y. Chen, and Z. Lv, "Dual-loop power control for single-phase grid-connected converters with LCL filters," Journal of Power Electronics, Vol. 11, No. 4, pp. 456-463, July. 2011.

[3] F. Blaabjerg, R. Teodorescu, M. Liserre, and A. V. Timbus, "Overview of control and grid synchronization for distributed power generation systems," IEEE Trans. Ind. Electron., Vol. 53, No. 5, pp. 1398-1409, Oct. 2006.

[4] R. Inzunza, T. Sumiya, Y. Fujii, and E. Ikawa, "Parallel connection of grid-connected LCL inverters for MW-scaled photovoltaic systems," in Proc. IEEE IPEC, pp. 1988-1993, 2010.

[5] T. Noguchi, H. Tomiki, S. Kondo, and I. Takahashi, "Direct power control of PWM converter without power-source voltage sensors," IEEE Trans. Ind. Appl., Vol. 34, No. 3, pp. 473-479, Mar./ Jun. 1998.

[6] D. Candusso, L. Valero, and A. Walter, "Modeling, control and simulation of a fuel cell based power supply system with energy management," in Proc. IEEE IECON, pp. 1294-1299, 2002.

[7] P. Mattavelli, G. Spiazzi, and P. Tenti, "Predictive digital control of power factor pre-regulators with input voltage estimation using disturbance observers," IEEE Trans. Power Electron., Vol. 21, No. 1, pp. 140-147, Jan. 2005.

[8] E. Twining and D. G. Holmes, "Grid current regulation of a three-phase voltage inverter with an LCL input filter," IEEE Trans. Power Electron., Vol. 18, No. 3, pp. 888-895, May 2003.

[9] R. Wu, S. B. Dewan, and G. R. Slemon, "Analysis of a PWM AC to DC voltage source converter under the predicted current control with a fixed switching frequency," IEEE Trans. Ind. Appl., Vol. 27, No. 4, pp. 756-763, Jul./Aug. 1991.

[10] L. Malesani, P. Mattavelli, and P. Tomasin, "Improved constant-frequency hysteresis current control of VSI inverters with simple feed-forward bandwidth prediction," IEEE Trans. Ind. Appl., Vol. 33, No. 5, pp. 1194-1202, Sep./Oct. 1997.

[11] K. Jalili and S. Bernet, "Design of LCL filters of active-front-end two-level voltage-source converters," IEEE Trans. Ind. Electron., Vol. 56, No. 5, pp. 1674-1689, May. 2009.

[12] I. J. Gabe, V. F. Montagner, and H. Pinheiro, "Design, and implementation of a robust current controller for VSI connected to the grid through an LCL filter," IEEE Trans. Power Electron., Vol. 24, No. 6, pp. 1444-1452, Jun. 2009. 
[13] L. A. Serpa, S. Ponnaluri, P. M. Barbosa, and J. W. Kolar, "A modified direct power control strategy allowing the connection of three-phase inverters to the grid through LCL filters," IEEE Trans. Ind. Appl., Vol. 43, No. 5, pp. 1388-1400, Sep./Oct. 2007.

[14] P. Rodriguez, A. V. Timbus, R. Teodorescu, M. Liserre, and F. Blaabjerg, "Flexible active power control of distributed power generation systems during grid faults," IEEE Trans. Ind. Electron., Vol. 54, No. 5, pp. 2583-2592, Oct. 2007.

[15] P. Rodriguez, A. Luna, I. Etxeberria-Otadui, R. Teodorescu, and F. Blaabjerg, "A stationary reference frame grid synchronization system for three-phase grid-connected power converters under adverse grid conditions," IEEE Trans. Power Electron., Vol. 27, No. 1, pp. 99-112, Jan. 2012.

[16] P. Rodriguez, J. Pou, J. Bergas, J. I. Candela, R. P. Burgos, and D. Boroyevich, "Decoupled double synchronous reference frame PLL for power converters control," IEEE Trans. Power Electron., Vol. 22, No. 2, pp. 584-592, Mar. 2007.

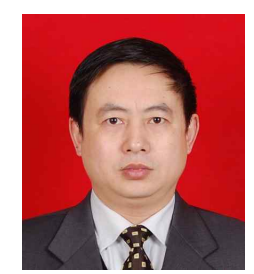

Lin Zhou was born in Sichuan, China, in 1961. He received his B.S., M.S., and Ph.D. in Electrical Engineering from Chongqing University, Chongqing, China, in 1984, 1988, and 2004, respectively. Since 1984, he has been engaged in teaching and scientific research in the fields of power electronic technology and power systems. From December 2008 to December 2009, he worked at Durham University as a Visiting Scholar, conducting research on micro-grids and renewable energy generation. His currently research interests include key technologies of distributed generation and power quality control.

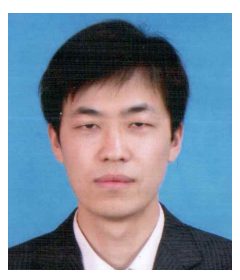

Ming Yang was born in Henan, China, in 1982. He received his B.S. and M.S. in Electrical Engineering and Automation from Henan Polytechnic University, Henan, China, in 2005 and 2008, respectively. From September 2008 to August 2010, he worked as a Teaching Assistant at Henan Polytechnic University. $\mathrm{He}$ is currently working toward his Ph.D. in Electrical Engineering at Chongqing University, Chongqing, China. His current research interests include modeling and control of photovoltaic inverters, and distributed generation technologies.

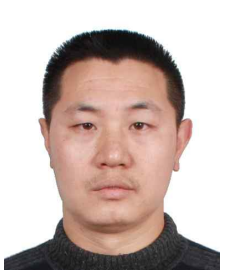

Qiang Liu was born in Liaoning, China, in 1976. He received his B.S. and M.S. in Electrical Engineering from Chongqing University, Chongqing, China, in 1999 and 2006, respectively. Since 1999, he has been engaged in teaching and scientific research in the fields of power electronic technology and power systems. $\mathrm{He}$ is currently working toward his Ph.D. in Electrical Engineering at Chongqing University. His current research interests include power converter control techniques, renewable energy and power quality.

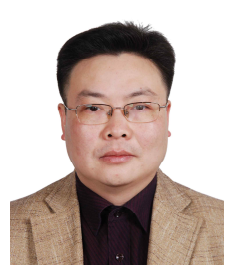

Ke Guo was born in Sichuan, China, in 1973. $\mathrm{He}$ received his B.S. and M.S. in Electrical Engineering from Chongqing University, Chongqing, China, in 1996 and 2008, respectively. Since 1996, he has been engaged in teaching and scientific research in the fields of power electronic technology and power systems. His currently research interests include the application of embedded systems and distributed generation. 